\title{
Optimal Sizing of a Photovoltaic-Hydrogen Power System for HALE Aircraft by means of Particle Swarm Optimization
}

\author{
Victor M. Sanchez, ${ }^{1}$ Romeli Barbosa, ${ }^{1}$ J. C. Cruz, ${ }^{2}$ F. Chan, ${ }^{1}$ and J. Hernandez ${ }^{1}$ \\ ${ }^{1}$ Universidad de Quintana Roo, Boulevard Bahía s/n, 77019 Chetumal, QROO, Mexico \\ ${ }^{2}$ Instituto Tecnológico de Chetumal, Avenida Insurgentes No. 330, 77013 Chetumal, QROO, Mexico \\ Correspondence should be addressed to Victor M. Sanchez; vicsan.huerta@gmail.com
}

Received 6 June 2014; Accepted 4 September 2014

Academic Editor: Baozhen Yao

Copyright (C) 2015 Victor M. Sanchez et al. This is an open access article distributed under the Creative Commons Attribution License, which permits unrestricted use, distribution, and reproduction in any medium, provided the original work is properly cited.

Over the last decade there has been a growing interest in the research of feasibility to use high altitude long endurance (HALE) aircrafts in order to provide mobile communications. The use of HALEs for telecommunication networks has the potential to deliver a wide range of communication services (from high-quality voice to high-definition videos, as well as high-data-rate wireless channels) cost effectively. One of the main challenges of this technology is to design its power supply system, which must provide the enough energy for long time flights in a reliable way. In this paper a photovoltaic/hydrogen system is proposed as power system for a HALE aircraft due its high power density characteristic. In order to obtain the optimal sizing for photovoltaic/hydrogen system a particle swarm optimizer (PSO) is used. As a case study, theoretical design of the photovoltaic/hydrogen power system for three different HALE aircrafts located at $18^{\circ}$ latitude is presented. At this latitude, the range of solar radiation intensity was from 310 to $450 \mathrm{Wh} / \mathrm{sq} \cdot \mathrm{m} /$ day. The results obtained show that the photovoltaic/hydrogen systems calculated by PSO can operate during one year with efficacies ranging between $45.82 \%$ and $47.81 \%$. The obtained sizing result ensures that the photovoltaic/hydrogen system supplies adequate energy for HALE aircrafts.

\section{Introduction}

Communication and energy technologies play an important role in the economic and social development of any nation. Furthermore, due to the increase in world population, bandwidth and energy consumption is growing. As an alternative to increasing the effectiveness of future communications, it has been proposed the use of high altitude long endurance (HALE) aircrafts, as liberators of bandwidth and enhancers of wireless communication [1-4].

Compared with satellite technology, HALE aircrafts, also known as high altitude platforms (HAPs) and high altitude aircraft and airships (HASS) have a cost of launching and operating smaller, higher capacity data transmission and increased spectral efficiency. Besides, they are considered as substitutes for low earth orbit (LEO) satellites. HALE aircrafts fly in the stratosphere, providing relay services for wireless communication networks with a single coverage area about $100 \mathrm{~km}$ in diameter [5]. In addition, there are a variety of specific applications regarding communications, monitoring large areas of interest, scientific applications, or other missions requiring high resolution images or data almost immediately.

HALE aircrafts are now being actively developed in a number of programmes all around the world [6]. Some relevant projects are Heliplat-HeliNet, SkyTower, SkyStation, SkyLARK, StratoSat, Pathfinder, Pathfinder plus, Centurion, Helios series, and the Zephyr series just to name a few [6, 7]. HALE aircrafts is an incipient technology yet; however the surge of recent activity reflects both the lucrative demand for wireless services as well as advances in solar cells and energy storage systems. In order to ensure project sustainability, including cost-effective benefits, the flight duration for a HALE aircraft must be continuous up to 6 months. This target only can reach it with a regenerative power system, for example, the power system studied in this paper.

In this way, the power subsystem is a key part that determines the implementation and feasibility of them. The use of 


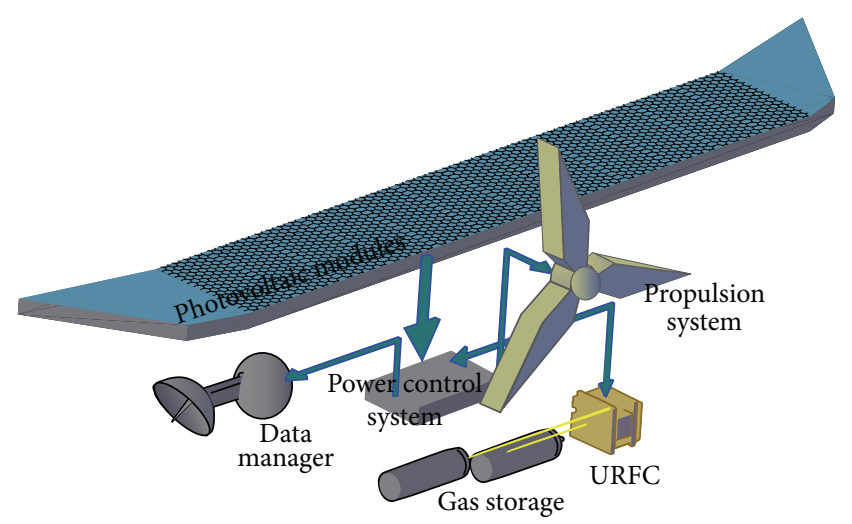

FIGURE 1: Energy flow diagram for HALE aircraft studied.

photovoltaic systems improves significantly the profitability and environmental efficiency of HALE [8]. However, due to its intermittency, solar energy requires a safe and reliable power storage system. One option to solve this problem is to use hydrogen as storage system of renewable energy. Hydrogen storage system is a viable option for many researchers [9], especially for mobile applications. Hydrogen is a suitable energy storage medium that is free of carbon and other impurities; it is also the most abundant element in the universe [10]. A system of production and energy storage based on hydrogen technology coupled with solar energy could provide greater efficacy to HALE aircraft because the closed loop system ensures long endurance and lightweight; furthermore the cost of hydrogen production and use has decreased in recent years.

Proton exchange membrane (PEM) technology (both fuel cells as electrolyzer) is by excellence the technology for an efficient consumption and generation of hydrogen [11]. On the other hand, unitized regenerative fuel cells (URFCs) are an excellent option in situations where weight and volume are a constraint. URFC is a compact electrochemical system integrated both by a fuel cell and a water electrolyzer. HALE aircraft powered by a subsystem based on solar cells and hydrogen (PVS-H2) should include a comprehensive storage system. Figure 1 shows a general diagram of a PVS-H2.

Power subsystem should be designed to satisfy two important requirements: (1) the propulsion and positioning of the aircraft and (2) the reception, handling, and transmission of information. The primary system produces electricity as long as the sun's radiation is present (PVS, composed of an array of photovoltaic panels). A control system (ACS) performs the management and conditioning of power generated according to the characteristics of the electrical load demand. The PVS must be designed in order to generate more energy during the day than the load consumes (energy surplus condition); the excess energy is used to produce hydrogen using the URFC (electrolyzer mode). This gas is stored in a storage media, for example, materials-based hydrogen storage system (MHSS). It is important to note that the development of new hydrogen storage technology is a current challenge for the global scientific community $[12,13]$. At night, electricity is generated by the URFC (fuel cell mode). On the other hand, the solar radiation reaching the earth's surface is reduced because a large part of it is scattered, reflected, or absorbed by the atmosphere. However, at the stratosphere, the solar radiation is characterized by high power and low intermittence [14]. Despite that, primary power system is not immune to low insolation level, gas leaks, or an URFC failure that cause hydrogen depletion, so that an emergency backup subsystem must be considered in order to provide the power for the safe landing of the aircraft.

The basic requirements for the sizing of the PVS-H2 system are to achieve maximum effectiveness as well as to ensure a reliable power supply. Power system sizing has to consider the steady-state characteristics and the profiles transient state of energy sources by location as well as the electrical load demand [13]. Regardless of the fact that, to ensure the survival of the aircraft, power system requires minimum error uncertainty to ensure at least the energy needed to control the position and rotation of the aircraft. On the other hand, due to the relationship between power required for flight and total weight, the optimal sizing of the PVS$\mathrm{H} 2$ energy system is essential to find one or more effective solutions that meet the operational goals.

This paper proposes the optimal sizing of an energy generating system for a HALE aircraft by means of PSO (particle swarm optimization). PSO is a population based stochastic optimization technique developed by Eberhart and Kennedy in 1995, which was inspired by the social behavior of animals [15]. Originally, PSO was intended to handle nonlinear continuous optimization problems. However due to its simple concepts, fast convergence speed, and easy implementation, PSO has been widely applied to solve intricate optimization problems of real-world engineering fields as in power systems issues [16-20]. The aim of this paper is to determine the optimal configuration of the power system that allows the flight of the HALE aircraft along one year with the best efficacy.

\section{Mathematical Formulation}

2.1. System's Global Efficacy. The design strategy consists of making an energy balance to evaluate the power system behavior. The system's efficiency $\left(\eta_{\mathrm{S}}\right)$ is calculated according to the first law of thermodynamics:

$$
\eta_{\mathrm{S}}=\frac{\left(\varepsilon_{\mathrm{out}}-\varepsilon_{s}\right)}{\varepsilon_{\mathrm{in}}}
$$

where $\varepsilon_{\text {out }}$ is the electrical energy consumed by the HALE aircraft, $\varepsilon_{\text {in }}$ is the electrical energy output of the PVS, and $\varepsilon_{s}$ is the electrical energy stored in the MHSS. $\varepsilon_{s}$ is negative when the hydrogen is produced for the URFC at electrolyzer mode and it is positive when the hydrogen is consumed by the URFC at fuel cell mode. In this work, $\eta_{S}$ is analyzed in hourly intervals; the average system efficiency $\left(\eta_{\text {s,mean }}\right)$ is calculated by

$$
\eta_{\mathrm{S} \text {,mean }}=\sum \frac{\eta_{\mathrm{S}}}{n},
$$

where $n$ is hours of the flight. The functionality of the system is defined by the ratio of the actual time of flight $\left(T_{\text {factual }}\right)$ 
to maximum time of flight $\left(T_{\mathrm{f}, \mathrm{max}}\right)$. Hence, system's global efficacy $\left(\mathrm{Eff}_{\mathrm{S}}\right)$ is determined by the following equation:

$$
\mathrm{Eff}_{\mathrm{S}}=\left[\frac{T_{\mathrm{f} \text {,actual }}}{T_{\mathrm{f} \text {,max }}}\right] \eta_{\mathrm{S} \text {,mean }},
$$

where $T_{\mathrm{f} \text { max }}$ is a constant that, in this work, is equal to 8640 (hours in a year). In this way, Eff $\mathrm{S}$ is in function of $\varepsilon_{\text {in }}, \varepsilon_{\text {out }}$, and $\varepsilon_{s}$.

2.2. Energy Input. The energy input $\left(\varepsilon_{\text {in }}\right)$ of the power subsystem is the energy output of the PVS. This energy is in function of the solar resource available on the site and the physical characteristics of the device, as is described by

$$
P_{\text {in }}=\eta_{\mathrm{PVS}} A_{\mathrm{PVS}} G_{i},
$$

where $\eta_{\mathrm{PVS}}$ is the instantaneous PVS efficiency, $A_{\mathrm{PVS}}$ is the total area of the PVS, and $G_{i}$ is the radiation on the PVS surface. Strictly, $\eta_{\mathrm{PVS}}$ is dependent on three parameters: the temperature, the packing factor, and the module reference efficiency. However, the efficiency used in this work is a global parameter of a hypothetical PVS $\left(\eta_{\mathrm{PVS}}=16 \%\right)$ [7]. $G_{i}$ depends on the time and latitude of the place; it can be calculated by [14]

$$
\begin{aligned}
G_{i}= & G_{\mathrm{SC}}\left[1+0.033 \cos \left(\frac{360 N}{365}\right)\right] \\
& \times[\sin (L) \sin (\delta)+\cos (L) \cos (\delta) \cos (h)],
\end{aligned}
$$

where $G_{i}$ is the extraterrestrial radiation measured on the plane normal to the radiation on the $N$ th day of the year, $G_{\mathrm{SC}}$ is the solar constant $\left(G_{\mathrm{SC}}=1366.1 \mathrm{~W} / \mathrm{m}^{2}\right.$ ASTM E-490), $N$ is the day of the year, $L$ is the latitude of the place, and $h$ is the solar hour. The solar declination $(\delta)$, in degrees for any day of the year $(N)$, is calculated approximately by [14]

$$
\delta=23.45 \sin \left[\frac{360}{365}(284+N)\right] .
$$

It is relevant to note that $G_{i}$ is strongly dependent on the latitude.

One hour time step is employed as base time in the energy balance for the aircraft power system, so that equivalence between power and energy is used as is specified in

$$
\begin{gathered}
\varepsilon_{\text {in }}=P_{\text {in }}, \\
\varepsilon_{\text {out }}=P_{\text {out }} .
\end{gathered}
$$

2.3. Hydrogen Energy Storage. Figure 2 shows a schematic diagram of the energy transport in the hydrogen storage system.

The hydrogen generated and consumed is in function of the surplus and deficit energy. According to the first law of thermodynamics, without electrochemistry considerations, the FC efficiency $\left(\eta_{\mathrm{FC}}\right)$ and the electrolyzer efficiency $\left(\eta_{\mathrm{PE}}\right)$ can be defined as follows:

$$
\begin{gathered}
\eta_{\mathrm{PE}}=\frac{\varepsilon_{\mathrm{NHg}}}{\varepsilon_{\text {surplus }}}, \\
\eta_{\mathrm{FC}}=\frac{\varepsilon_{\text {deficit }}}{\varepsilon_{\mathrm{NHc}}},
\end{gathered}
$$

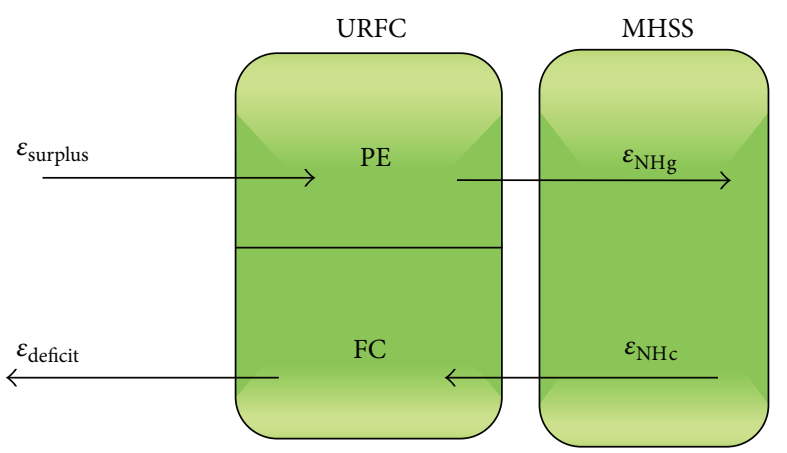

FIGURE 2: Energy transformation diagram of the hydrogen technology system.

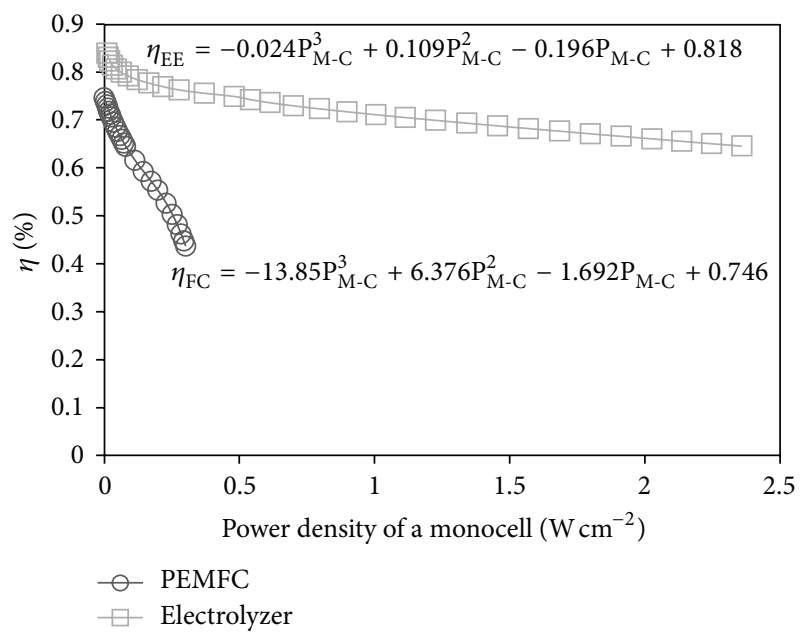

FIGURE 3: Performance and extrapolation equation of the experimental PEMFC and electrolyzer efficiency values with respect to the power density of a monocell.

where $\varepsilon_{\mathrm{NHg}}$ is the electrical energy of hydrogen generated by electrolyzer $(\mathrm{PE}), \varepsilon_{\text {surplus }}$ is the energy surplus, $\varepsilon_{\text {deficit }}$ is the energy deficit, and $\varepsilon_{\mathrm{NHc}}$ is the electrical energy of hydrogen consumed by fuel cell (FC). On the other hand, $\varepsilon_{s}$ can be determined by the energy balance of

$$
\varepsilon_{s}=\varepsilon_{\mathrm{NHg}}-\varepsilon_{\mathrm{NHc}} \cdot
$$

By substitution of (8) into (9), a mathematical relation that determines $\varepsilon_{s}$ as a function of the URFC efficiency, as well as of the surplus and deficit energies, is obtained in

$$
\varepsilon_{s}=\eta_{\mathrm{PE}} \varepsilon_{\text {surplus }}-\frac{\varepsilon_{\mathrm{deficit}}}{\eta_{\mathrm{FC}}} .
$$

In this work, the real efficiency of a monocell is extrapolated in order to find both efficiencies $\left(\eta_{\mathrm{PE}}\right.$ and $\left.\eta_{\mathrm{FC}}\right)$. Figure 3 shows the performance and extrapolation equation of PEMFC and electrolyzer used in this work, which were obtained by experimental polarization curves carried out in our laboratory.

2.4. Energy Output. The electric energy output $\left(\varepsilon_{\text {out }}\right)$ of the HALE aircraft is a function of the power consumed by the 
propeller $\left(P_{\mathrm{TL}}\right)$. $P_{\mathrm{TL}}$ can be described by a mathematical model based on point mass dynamics. In steady flight and in still air, the lift $(L)$ and the drag $(D)$ forces are defined as follows [21]:

$$
\begin{aligned}
L & =C_{L} S_{W}\left(\frac{\rho}{2}\right) V^{2}, \\
D & =C_{D} S_{W}\left(\frac{\rho}{2}\right) V^{2},
\end{aligned}
$$

where $C_{L}$ and $C_{D}$ are the lift and drag coefficients, respectively, $\rho$ is the air density, $S_{W}$ is the wing area, and $V$ is the relative airspeed. The $C_{L}$ and $C_{D}$ heavily depend on the airfoil, the angle of attack, and the Reynolds number. In this work, these coefficients are taken from [7], where $C_{L}, C_{D}$, and $\rho$ are calculated by the "aerodynamic parameters analysis" method. At straight and level flight, according to the third Newton law, the lift force compensates for the weight $(W)$ and the propeller thrust compensates for the drag force; thus the power for level flight $\left(P_{\mathrm{TL}}\right)$ can be calculated by [21]

$$
P_{\mathrm{TL}}=C_{D}\left(\frac{W}{C_{L}}\right)^{3 / 2}\left(\frac{2}{\rho S}\right)^{1 / 2}
$$
$\left(\eta_{\mathrm{PP}}\right)$ :

Then, $\varepsilon_{\text {out }}$ can be calculated by the propeller efficiency

$$
\varepsilon_{\mathrm{out}}=\frac{t P_{\mathrm{TL}}}{\eta_{\mathrm{PP}}} .
$$

By substitution of (4), (9), and (13) in (1), we determined the system's efficiency $\left(\eta_{\mathrm{S}}\right)$ and therefore its global efficacy $\left(\mathrm{Eff}_{\mathrm{S}}\right)$.

\section{Basics on the PSO Algorithm}

A PSO algorithm consists of a population continuously updating the knowledge of the given searching space. This population is formed by individuals called particles. Each one represents a possible solution finding the global best position by competition as well as cooperation among themselves after some iteration. Each particle keeps track of its coordinates in the problem space which are associated with the best solution (fitness) it has achieved so far. This value is called pbest. Overall best value is tracked by the global version of the particle swarm optimizer also and its location, obtained so far by any particle in the population. This location is called gbest. Each particle moves in the searching space with a velocity $V$, which is dynamically updated based on its previous velocity. At each time step, each particle moves toward its pbest and gbest locations. Acceleration is weighted by a random term, with separate random numbers being generated for acceleration toward pbest and gbest locations, as is described in

$$
\begin{aligned}
V_{i, j}^{\mathrm{iter}+1}= & w V_{i, j}^{\mathrm{iter}}+C_{1} * \text { rand }() \\
& *\left(\text { pbest }-X_{i}\right)+C_{2} * \operatorname{Rand}() *\left(\text { gbest }-X_{i}\right) \\
& \quad \text { for } i=1,2, \ldots, \text { NIND } ; j=1,2, \ldots, \text { NVAR, }
\end{aligned}
$$

TABLE 1: Hale aircrafts specifications taken from [19].

\begin{tabular}{lccc}
\hline Aircraft & Total mass $(\mathrm{kg})$ & Empty mass $(\mathrm{kg})$ & Wing area $\left(\mathrm{m}^{2}\right)$ \\
\hline Pathfinder & 252 & 207 & 70.8 \\
Pathfinder + & 315 & 247 & 87.1 \\
Helios HP01 & 719 & 600 & 186.6 \\
\hline
\end{tabular}

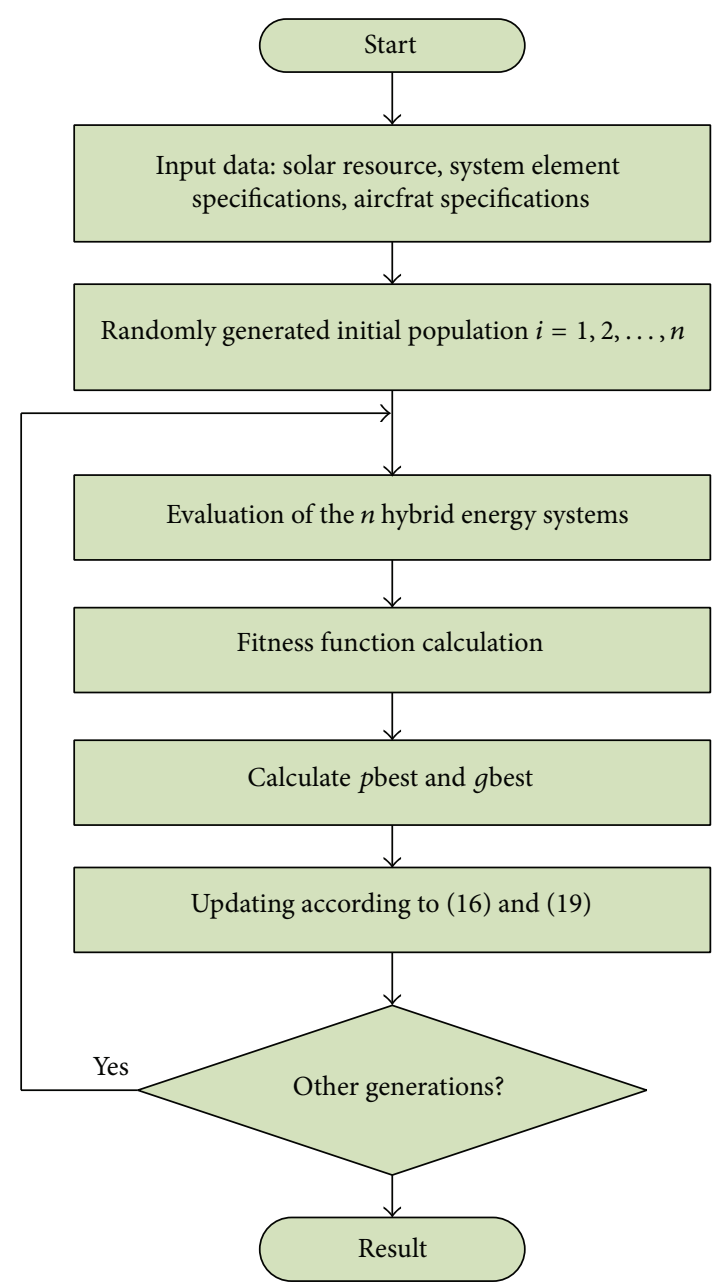

FIGURE 4: Flowchart of the optimization process.

where $V$ is the particle's velocity; iter is the current iteration; $C_{1}$ and $C_{2}$ are two positive learning factors; $X_{i}$ is the $i$ th particle's actual position; rand() and Rand() are two randomly generated values within the range $[0,1]$; NIND is the number of particles; NVAR is the number of variables and $w$ is known as the inertia weight. It plays the role of balancing the global and local searching [22]. In order to avoid a premature convergence problem in PSO, a linearly decreased inertia weight over time is used for this parameter.

The position of particles is updated during each iteration. This is done by adding the velocity value to the particle's position as follows:

$$
X_{i, j}^{\mathrm{iter}+1}=X_{i, j}^{\mathrm{iter}}+V_{i, j}^{\mathrm{iter}+1}
$$


TABLE 2: Input data used for the cases of study.

\begin{tabular}{lccl}
\hline Parameter & Value & Unit & Description \\
\hline$M_{\text {ctr }}$ & 8 & $\mathrm{~kg}$ & Mass of control, energy manage, and communication system \\
$N$ & $1<N \leq 360$ & day & Days of the year \\
$h$ & $1<h \leq 24$ & $\mathrm{~h}$ & Hours of a day \\
$G_{\mathrm{SC}}$ & 1366.1 & $\mathrm{~W} / \mathrm{m}^{2}$ & Solar constant (ASTM E-490) \\
$C_{D}$ & 0.028 & - & Drag coefficient (20 km altitude, $29.49 \mathrm{~m} / \mathrm{s}$ level flight velocity and 155185 Re number) [17] \\
$\mathrm{L} / \mathrm{D}$ & 28.5 & - & Ratio of lift-drag (20 km altitude, $29.49 \mathrm{~m} / \mathrm{s}$ level flight velocity and 155185 Re number) [17] \\
$\eta_{\mathrm{PP}}$ & 0.6 & - & Efficiency of propulsion system \\
$\eta_{\mathrm{PVS}}$ & 0.15 & - & Efficiency of photovoltaic system \\
$\omega_{\mathrm{PVS}}$ & 1 & $\mathrm{~kg} / \mathrm{m}^{2}$ & Mass density of solar cells \\
$\omega_{\mathrm{URFC}}$ & 1500 & $\mathrm{~W} / \mathrm{kg}$ & Specific power density of URFC \\
\hline
\end{tabular}

This process is repeated until a criterion is met, usually a sufficiently good fitness or a maximum number of iterations.

3.1. PSO Analysis Strategy. The main objective of energy system's sizing is to determine the most efficient configuration that allows aircrafts to fly during one year. For this reason, we propose a maximization of the power system efficacy as is described by the objective function stated by (16) and which is based on (3):

$$
F^{\mathrm{obj}}=\max \left[\left(\frac{\sum_{i=1}^{m} T_{\mathrm{f}, \mathrm{actual}, i}}{T_{\mathrm{f}, \max }}\right) \frac{\sum_{j=\mathrm{PVS}, \mathrm{URFC}, \mathrm{MSS}, \mathrm{ctrl}, \text { structure }}\left(P_{\mathrm{TL}}=f\left(W_{j}\right)\right)+\sum_{k=\min }^{n} P_{\mathrm{ss}, k}}{\sum_{l=1}^{n} P_{\mathrm{PV}, l}}\right] .
$$

Hence, the optimal configuration for the energy system must satisfy the flight of the aircraft during one year with the best efficacy. As we can note in (16), for a given photovoltaic power, the overall efficiency decreases if an oversizing of the system's elements occurs due to that this means more weight on the aircraft.

3.2. Operating Constraints. The first constraint is related to the maximum weight that the aircraft can transport and which is denoted by

$$
\sum_{j=\text { PVS,URFC,ctrl,structure }} W_{j} \leq W_{\text {aircraft,max }} \cdot
$$

On the other hand, the second constraint is the total area available for the photovoltaic panels and which is constrained by the area on the aircraft wings:

$$
\sum_{l=1}^{o} A_{\mathrm{PVS}} \leq A_{\text {wing,max }}
$$

3.3. Fitness Function. Different techniques for handling constraints in evolutionary algorithms have been proposed in the literature [23]. In this work, constraints are handled by penalizing the objective function. Using this technique, the fitness function is constituted by the objective function plus the penalization terms, as follows:

$$
\begin{aligned}
F^{\text {fitness }}= & F^{\text {obj }} \\
& - \text { abs }\left\{\sum_{n=1}^{i}\left(K_{1}\left(\sum_{\text {PVS,URFC,ctrl,structure }} W_{j}\right)\right)\right\},
\end{aligned}
$$

where $K_{1}$ is a penalization constant and $W_{j}$ is the weight of the power system evaluated in order to find the maximum efficacy. In each PSO iteration, particular systems formed by the $n$ particles are evaluated to meet the flight time of the aircraft during the year with the best efficacy.

The flowchart of the proposed optimization process is depicted in Figure 4.

The main steps of the proposed optimization process are described in the following subsections.

3.4. Input Data and Initial Population of the PSO. The input data for optimizing the energy system by PSO are the solar resource available at the site as well as aircraft specifications and power system elements. The PSO determines the optimal configuration by evaluating photovoltaic, fuel cell and storage powers needed to maintain the aircraft flying. The optimizer generates three vectors with $n$ particles each one (in this paper $n=50$ particles), where each vector represents the photovoltaic, fuel cell and storage powers. Each power system is evaluated over a period of 8640 hours with the operating strategy depicted in Figure 5. 


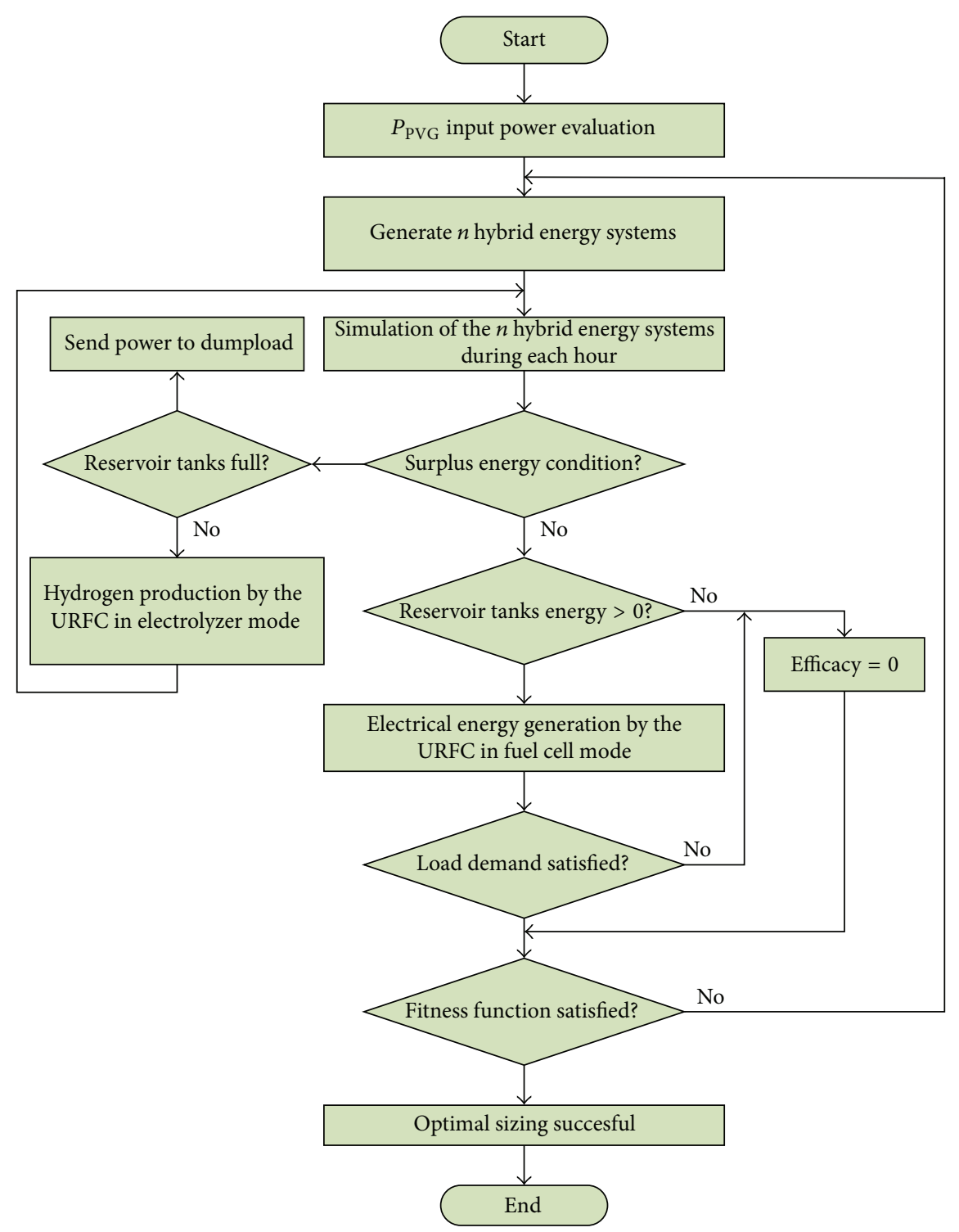

FIGURE 5: Flowchart of the energy management strategy for optimal sizing.

\section{Cases of Study and Computational Results}

In order to validate the sizing strategy for the energy system proposed in this work, we have selected three HALE aircrafts as benchmark test. The total mass, empty mass, and wing area of the HALE aircrafts were obtained from the open literature and they are shown in Table 1 [7].

We have selected Chetumal city, Mexico ( $18^{\circ}$ latitude), as testing site in order to estimate the solar resource available by means of (5). One annual cycle is used as period of time for the analysis in this study. Table 2 shows other input data assumed in this work.

On the other hand, Table 3 shows the PSO parameters used in order to solve the sizing problem. A linear decreasing function for the inertia term is used in order to reduce the influence of past velocities.
TABLE 3: PSO parameters.

\begin{tabular}{lcc}
\hline Item & Symbol & Value \\
\hline Particles & - & 50 \\
Maximum number of iterations & - & 300 \\
Acceleration constants & $C_{1}$ & 2 \\
Initial inertia weight & $C_{2}$ & 2 \\
Final inertia weight & $w_{b}$ & 0.9 \\
\hline
\end{tabular}

A set of ten simulations for the power system sizing of each HALE aircraft was performed in order to obtain trustworthy results, due to the stochastic nature of the PSO. Thereby, Figure 6 shows the PSO convergence rate for the efficacy maximization of the HALE aircrafts power systems. 
TABLE 4: Cases of study results.

\begin{tabular}{|c|c|c|c|c|c|c|}
\hline Aircraft & & PPVS/kW & PSS/kWh & PURFC/kW & MASS/kg & EFFS/\% \\
\hline \multirow{4}{*}{ Pathfinder } & Mean & 5.37 & 24.49 & 11.51 & 191.01 & 46.82 \\
\hline & $\begin{array}{l}\text { StDev } \\
(\mathrm{CV})\end{array}$ & $\begin{array}{c}0.25 \\
(4.6 \%)\end{array}$ & $\begin{array}{c}3.90 \\
(15.9 \%)\end{array}$ & $\begin{array}{c}1.50 \\
(13.0 \%)\end{array}$ & $\begin{array}{c}5.16 \\
(2.7 \%)\end{array}$ & $\begin{array}{c}1.05 \\
(2.2 \%)\end{array}$ \\
\hline & Min & 5.20 & 22.92 & 8.38 & 187.92 & 44.55 \\
\hline & Max & 5.97 & 35.18 & 12.22 & 205.36 & 47.60 \\
\hline \multirow{4}{*}{ Pathfinder plus } & Mean & 6.04 & 32.36 & 15.01 & 224.09 & 47.81 \\
\hline & $\begin{array}{l}\text { StDev } \\
(\mathrm{CV})\end{array}$ & $\begin{array}{c}0.33 \\
(5.4 \%)\end{array}$ & $\begin{array}{c}6.04 \\
(18.7 \%)\end{array}$ & $\begin{array}{c}0.95 \\
(6.3 \%)\end{array}$ & $\begin{array}{c}7.69 \\
(3.4 \%)\end{array}$ & $\begin{array}{c}0.46 \\
(1.0 \%)\end{array}$ \\
\hline & Min & 5.80 & 28.88 & 12.40 & 217.77 & 46.90 \\
\hline & Max & 6.70 & 44.33 & 15.40 & 238.66 & 48.28 \\
\hline \multirow{4}{*}{ Helios HP01 } & Mean & 18.31 & 88.88 & 33.58 & 589.91 & 45.82 \\
\hline & $\begin{array}{l}\text { StDev } \\
(\mathrm{CV})\end{array}$ & $\begin{array}{c}0.80 \\
(4.4 \%)\end{array}$ & $\begin{array}{c}11.19 \\
(12.6 \%)\end{array}$ & $\begin{array}{c}4.01 \\
(12.0 \%)\end{array}$ & $\begin{array}{l}14.89 \\
(2.5 \%)\end{array}$ & $\begin{array}{c}0.92 \\
(2.0 \%)\end{array}$ \\
\hline & Min & 17.10 & 73.81 & 24.35 & 565.60 & 44.22 \\
\hline & Max & 20.01 & 104.44 & 36.28 & 608.09 & 46.80 \\
\hline
\end{tabular}

Table 4 presents the optimization results of each study. Nominal powers of PVS (PPVS), storage system (PSS), URFC (PURFC), HALE total mass, and global efficacy values are shown in the columns of Table 4. A statistical analysis is performed on the results obtained for each HALE aircraft studied. Mean values, standard deviation, and maximum and minimum values are shown also.

A variation coefficient $(\mathrm{CV})$ is used as an indicator of the difference between the standard deviation and the mean value in each case study. According to $\mathrm{CV}$ value, the results obtained by PSO show a low dispersion.

The optimization results indicate that a mean value of $46.82 \%$ for the efficacy is obtained for HALE Pathfinder, with an energy power system of $5.37 \mathrm{~kW}, 24.29 \mathrm{kWh}$, and $11.51 \mathrm{~kW}$, for PPVS, PSS, and PURFC, respectively. This configuration implicates a total mass of $191 \mathrm{~kg}$ (mean value) for HALE aircraft, which represents $60.99 \mathrm{~kg}(24.2 \%)$ less than the original total mass according to Table 1.

Similarly, the results obtained indicate that the total mass for the Pathfinder Plus mass is $90.91 \mathrm{~kg}$ (28.86\%) lighter with respect to the total mass reported in Table 1 . The same case occurs with HELIOS HP1; the optimized configuration of the energy power system implicates an aircraft $129.09 \mathrm{~kg}$ (17.95\%) more light. These results do not mean an increase of extrapayload; however, it would be used as a redesign parameter for the aircraft's structure. It is noteworthy that maximum and minimum values for the efficacy and the total mass are not associated with the power capacities of the power system elements that form the optimized configurations (PPVS, PSS, and PURFC).

Finally, the variation coefficient value has a maximum deviation for the storage power system (PSS, CV =18.7\% @ Pathfinder plus), whereas a less deviation of this parameter is obtained for PPVS (CV = 4.4\% @ Helios HP01). Nevertheless, this parameter has small variations in efficacy and total mass values $(2.2 \%$ and $3.4 \%$, resp.).

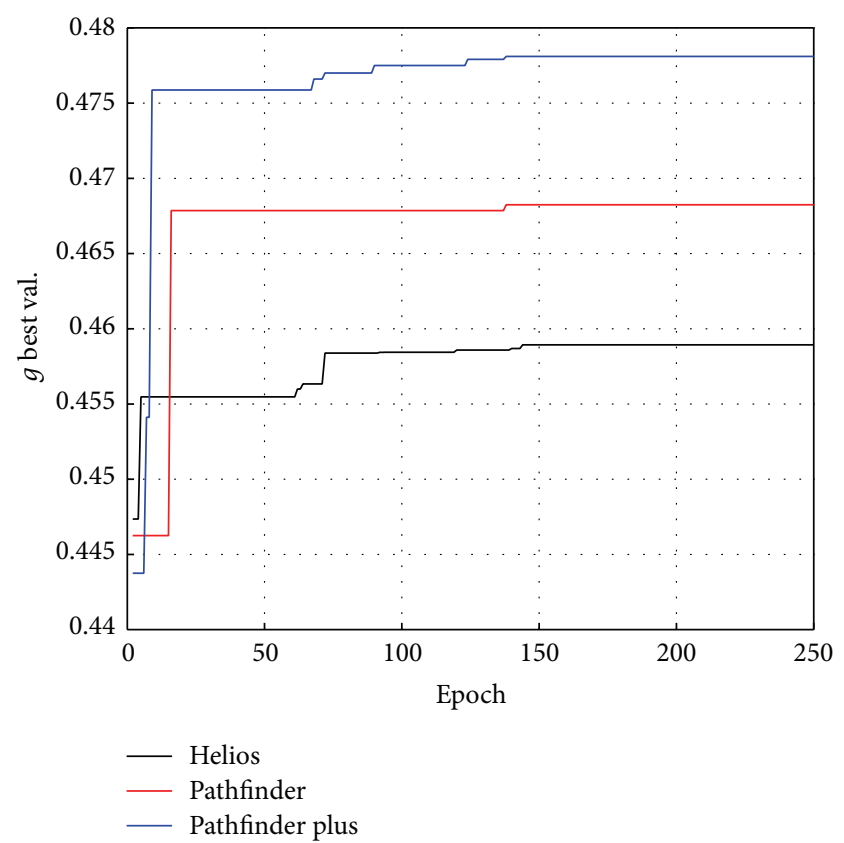

FIGURE 6: Convergence rate for PSO algorithm.

\section{Conclusions}

This paper has provided the optimal sizing of the energy power supply for HALE aircrafts by means of PSO. The method proposed allows an easy way to obtain the optimal configuration for the energy power system without deep knowledge about the relationship between the power generated by energy system elements, electric power demanded for the propeller, and HALE aircraft mass. Furthermore, optimal configurations for the photovoltaic/hydrogen systems consider the system thermodynamic efficiency during an annual cycle, and experimental data of local weather and the 
electrochemical performance of the URFC were considered in the energy balance. On the other hand, although simplified models have been used for the power system components, the results obtained by the proposed approach enable the identification of opportunities for improvement of the design of HALE aircrafts. The results obtained demonstrate that the optimal sizing of the power system is in function of each component's weight. Besides, for the three HALE aircrafts the efficacy of the optimal power systems ranges between $45.82 \%$ to $47.81 \%$. This result highlights the adequate combination of solar energy with hydrogen technology.

Also, we must note that the required PPVS is comparatively less than the PURFC in the power systems optimized, which shows an opportunity area to improve the power density in URFCs. Finally, the results obtained by PSO show a low dispersion, which demonstrates the robustness of the optimization process proposed in this work; besides that they contribute to the future implementation of HALE aircrafts in telecommunication applications.

\section{Conflict of Interests}

The authors declare that there is no conflict of interests regarding the publication of this paper.

\section{Acknowledgments}

The authors wish to thank PROMEP, CONACYT and Quintana Roo Government for supporting this project under Grants UQROO-EXB-072, Fordecyt 116157, and QR00-2011001-174895, respectively.

\section{References}

[1] S. Ohmori, Y. Yamao, and N. Nakajima, "Future generations of mobile communications based on broadband access technologies," IEEE Communications Magazine, vol. 38, no. 12, pp. 134$142,2000$.

[2] T. C. Tozer and D. Grace, "High-altitude platforms for wireless communications," Electronics \& Communication Engineering Journal, vol. 13, no. 3, pp. 127-137, 2001.

[3] T. Van Do, G. Buchholcz, L. Juhász, and J. Pakai, "Providing telecommunications services for rural areas from the HAP (High Altitude Platform): a case study in the region of Hungary," in Proceedings of the Telecommunications Network Strategy and Planning Symposium, pp. 1-5, November 2006.

[4] Z. Yang and A. Mohammed, "Wireless communications from high altitude platforms: applications, deployment and development," in Proceedings of the IEEE 12th International Conference on Communication Technology (ICCT '10), pp. 1476-1479, Nanjing, China, November 2010.

[5] G. M. Djuknic, J. Freidenfelds, and Y. Okunev, "Establishing wireless communications services via high-altitude aeronautical platforms: a concept whose time has come?" IEEE Communications Magazine, vol. 35, no. 9, pp. 128-135, 1997.

[6] S. D. Ilcev, "Stratospheric communication platforms as an alternative for space program," Aircraft Engineering and Aerospace Technology, vol. 83, no. 2, pp. 105-111, 2011.

[7] G. Xian-Zhong, H. Zhong-Xi, G. Zheng, Z. Xiong-Feng, L. JianXia, and C. Xiao-Qian, "Parameters determination for concept design of solar-powered, high-altitude long-endurance UAV," Aircraft Engineering and Aerospace Technology, vol. 85, no. 4, pp. 293-303, 2013.

[8] S. Jashnani, T. R. Nada, M. Ishfaq, A. Khamker, and P. Shaholia, "Sizing and preliminary hardware testing of solar powered UAV," The Egyptian Journal of Remote Sensing and Space Science, vol. 16, no. 2, pp. 189-198, 2013.

[9] O. Erdinc and M. Uzunoglu, "Recent trends in PEM fuel cellpowered hybrid systems: investigation of application areas, design architectures and energy management approaches," Renewable and Sustainable Energy Reviews, vol. 14, no. 9, pp. 2874-2884, 2010.

[10] B. Khandelwal, A. Karakurt, P. R. Sekaran, V. Sethi, and R. Singh, "Hydrogen powered aircraft: the future of air transport," Progress in Aerospace Sciences, vol. 60, pp. 45-59, 2013.

[11] G. Gahleitner, "Hydrogen from renewable electricity: An international review of power-to-gas pilot plants for stationary applications," International Journal of Hydrogen Energy, vol. 38, no. 5, pp. 2039-2061, 2013.

[12] S. Dutta, "A review on production, storage of hydrogen and its utilization as an energy resource," Journal of Industrial and Engineering Chemistry, vol. 20, no. 4, pp. 1148-1156, 2014.

[13] M. A. Elhadidy and S. M. Shaahid, "Promoting applications of hybrid (wind+photovoltaic+diesel+battery) power systems in hot regions," Renewable Energy, vol. 29, no. 4, pp. 517-528, 2004.

[14] S. Kalogirou, Solar Energy Engineering: Process and Systems, Elsevier, London, UK, 1st edition, 2009.

[15] R. Eberhart and J. Kennedy, "A new optimizer using particle swarm theory," in Proceedings of the 6th International Symposium on Micro Machine and Human Science (MHS '95), pp. 3943, Nagoya, Japan, October 1995.

[16] L. L. Lai, Intelligent System Applications in Power EngineeringEvolutionary Programming and Neural Networks, John Wiley \& Sons, New York, NY, USA, 1998.

[17] M. R. Al-Rashidi and M. E. El-Hawary, "A survey of particle swarm optimization applications in electric power systems," IEEE Transactions on Evolutionary Computation, vol. 13, no. 4, pp. 913-918, 2009.

[18] K. Mahadevan and P. S. Kannan, "Comprehensive learning particle swarm optimization for reactive power dispatch," Applied Soft Computing Journal, vol. 10, no. 2, pp. 641-652, 2010.

[19] S. M. Hakimi and S. M. Moghaddas-Tafreshi, "Optimal sizing of a stand-alone hybrid power system via particle swarm optimization for Kahnouj area in south-east of Iran," Renewable Energy, vol. 34, no. 7, pp. 1855-1862, 2009.

[20] A. Y. Alanis, E. Rangel, J. Rivera, N. Arana-Daniel, and C. Lopez-Franco, "Particle swarm based approach of a real-time discrete neural identifier for linear induction motors," Mathematical Problems in Engineering, vol. 2013, Article ID 715094, 9 pages, 2013.

[21] X. Z. Gao, Z. X. Hou, Z. Guo, J. X. Liu, and X. Q. Chen, "Energy management strategy for solar-powered high-altitude long-endurance aircraft," Energy Conversion and Management, vol. 70, pp. 20-30, 2013.

[22] Y. H. Shiand and R. C. Eberhart, "Parameter selection in particle swarm optimizer," in Proceedings of the 7th Annual Conference Evolutionary Programming, pp. 25-27, 1998.

[23] Z. Michalewicz, N. Attia, A. V. Sebald, and L. Fogel, "Evolutionary optimization of constrained problems," in Proceedings of the 3rd Annual Conference Evolutionary Programming, pp. 98-108, 1994. 


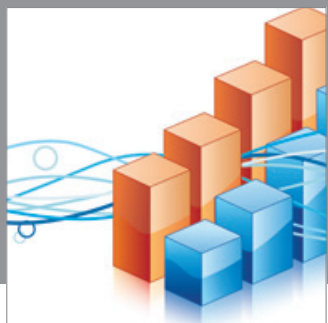

Advances in

Operations Research

mansans

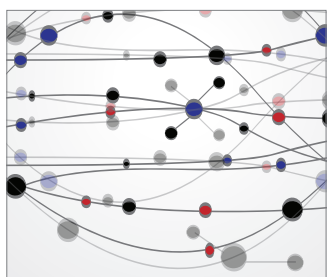

The Scientific World Journal
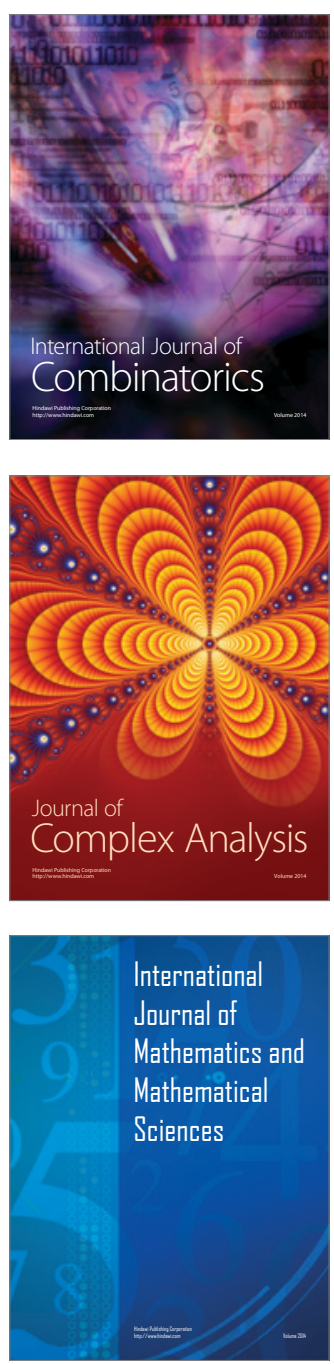
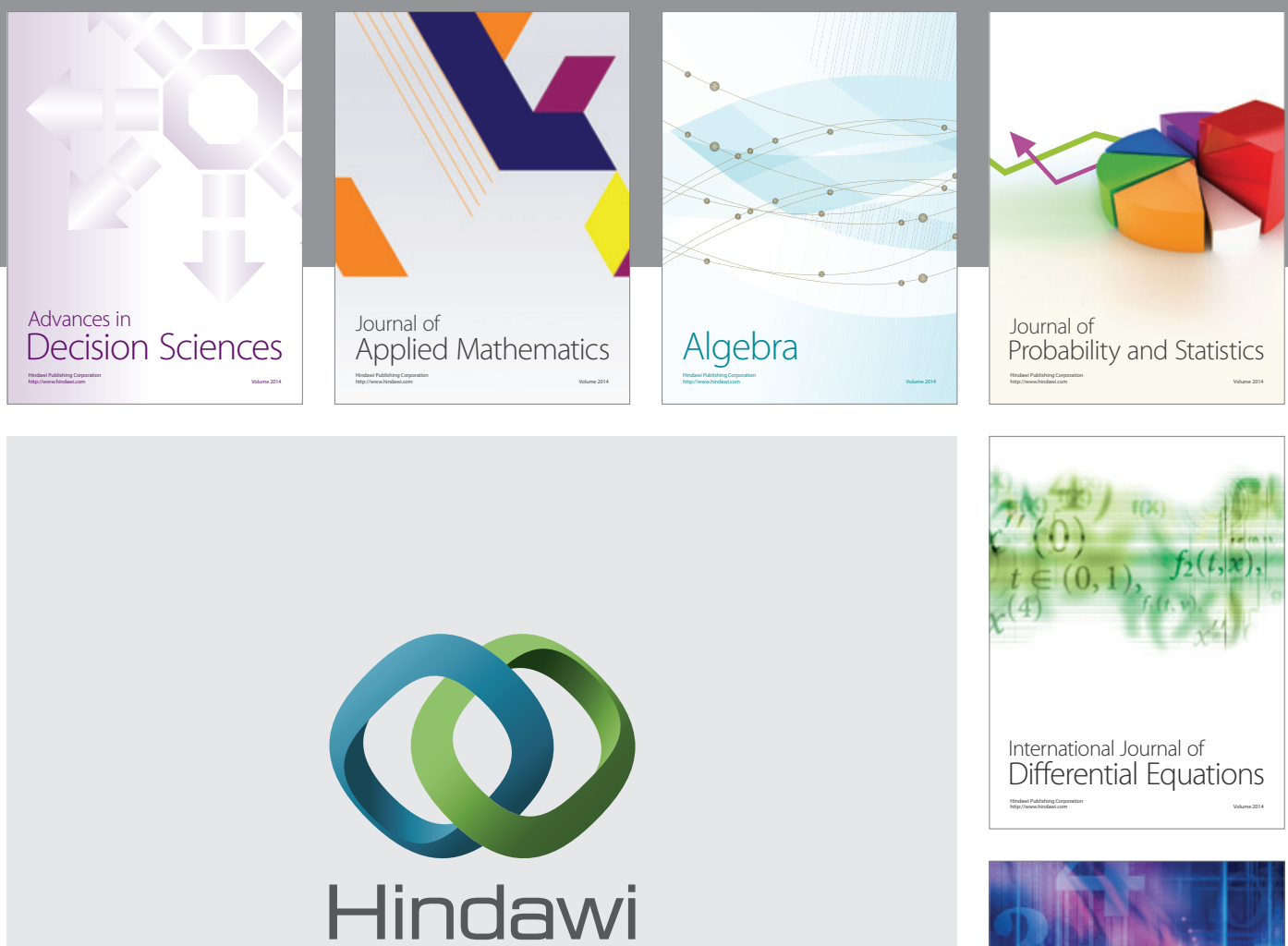

Submit your manuscripts at http://www.hindawi.com
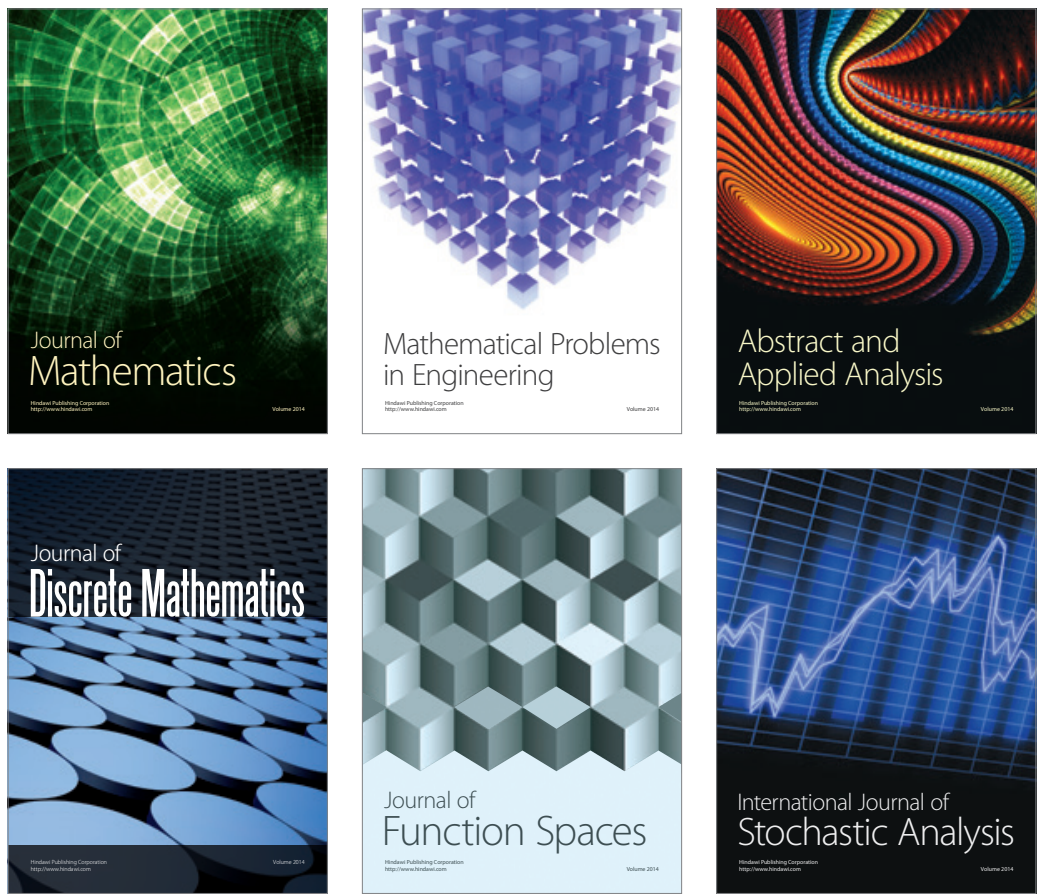

Journal of

Function Spaces

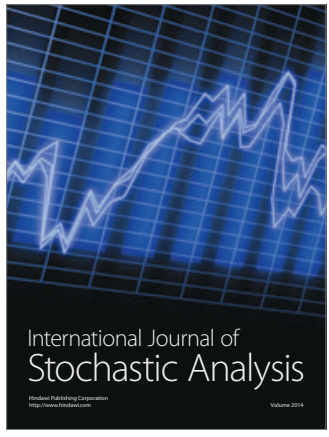

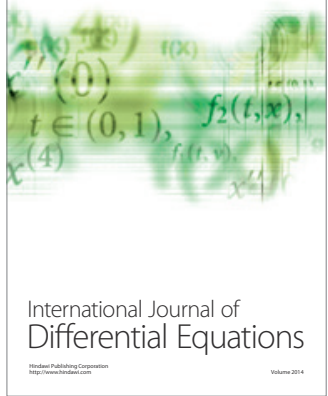
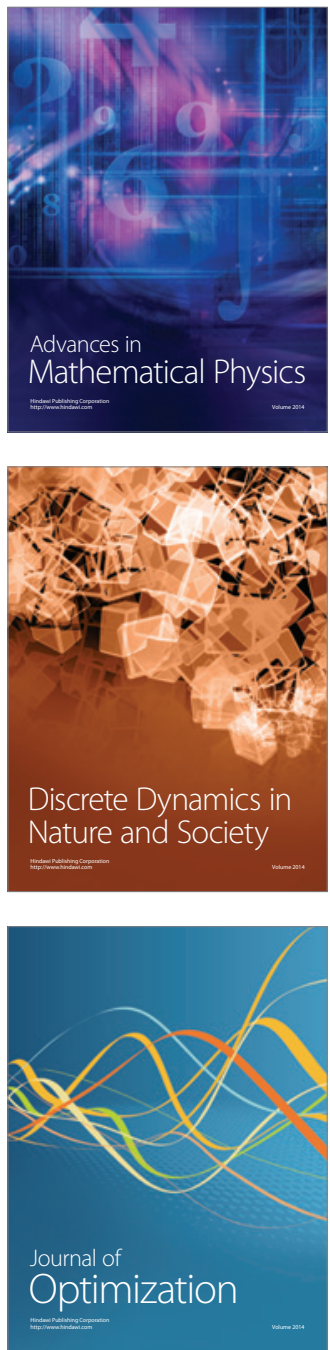